\title{
From inter-agency to multidisciplinary work in a sector generic mental health team
}

\author{
S. Marriott, A. Hassiotis, J. Ray and P. Tyrer
}

\begin{abstract}
The ellocts of edtablishing a full multidisciplinary community poychiotilic tecm in central London ore described. The noture of referrots, and referrers' sattifaction with the service were excmined duting two comparable stx-month periods, betore and afier the changes. The number and sovertly of referrats Increased, and reterrers were more soitsiled with the now senvice. In contraet to the inter-agency model, the now mullidisciplinary team was asecciated with more appropriate refiend of thoes polients with the greated need for spectellist services. Cinical skiti mbx in the fecm and reterrer education are the two foctions moet likely to hove promoted thees important changes. The koy role of the peychlatitut in a fill multidiscipinnary tean who con empower mulli-profesedonal case managers in their doy-to-doy manogement of severely if patients is highllighted.
\end{abstract}

The last forty years have seen a progresstve expansion in the number and diversity of community-based mental health agencies, including those provided by community psychiatric nurses, mental health social workers, and through liaison with primary care. The accessibility (Marriott et al, 1993) and acceptability (Merson et al, 1992) of these services may be greater than for more traditional services. However, the risk of specialist services becoming overwhelmed by the demands of mild psychiatric disorders (Donovan, 1982). while services for the severely mentally ill fragment between agencies (Ritchie et al, 1994) are considerable. Increasing the range of services does not mean they are necessarily more appropriate.

With these changes, professionals are looking for better ways of working together, both within and across service boundaries. Multidisciplinary working describes a model of service deltvery in which health care professionals work together in a team, share a common philosophy of care and tailor their care to the needs of the individuals or population they serve (Cooper, 1990). However, little is known of the skdll mix a team needs to provide the most effective care to people with severe mental health needs across community and hospital settings. Referral education as a means to promoting better use of specialist services, for instance between primary and secondary care, has been evaluated in a range of settings, and among other factors this evaluation has focused interest on the role of referral guidelines in changing service users' behaviour (Effective Health Care, 1994).

This study examines the implications of implementing a new model of service delivery into an existing community-based team, and considers the particular role that a psychiatrist may have in the assessment and management of a multidisciplinary team's caseload.

\section{The study}

The north Marylebone sector in central London comprises a total population of 57 400. Jarman (Jarman, 1983) indices range from 9.46 (Regent's Park) to 40.1 (Church Street) and there is a diverse mix of ethnic groups, of which $70 \%$ are white. The sector includes three hostels for homeless people, and a significant proportion of the population is not registered with a general practitioner (GP).

\section{An inter-agency model of service [Time 1]}

A team of community psychiatric nurses established in 1987 developed further by appointing an occupational therapist and two social workers, eventually totalling seven case managers and one full-time administrator. The team provided an open referral system to patients over the age of 16. suffering from any mental disorder except a primary alcohol or drug problem. In the absence of the team's own psychiatrist, referrals were always under the medical care of local GPs and local hospital consultants.

The multidisciplinary model of service [Time 2] In accordance with the need to develop services, prioritising those with severe mental health problems, a full-time psychiatrist was appointed, followed by a sessional psychologist, and audit administrator. Social workers were appointed. and a coterminous health and social service 
Table 1. Comparison of rates of referral of severe and non-severe mental illness, and referral Global Assessment Scale (GAS) score at initial contact between Time 1 and Time 2

\begin{tabular}{llll}
\hline & $\pi m 01(\%)$ & $\pi m e 2(\%)$ & \\
\hline Severe & 30.4 & 49.5 & $\chi^{2}=4.57$ d.f. $=1$ \\
& $(n=14)$ & $(n=47)$ & $P=0.05$ \\
Non-severe & 69.9 & 50.5 & \\
GAS & $(n=32)$ & $(n=49)$ & \\
& 49.5 (s.d. $=17.3)$ & $47.5($ s.d. $=18.4)$ & $\quad t=0.54 P=0.6$ \\
& $(n=35)$ & $(n=90)$ & \\
\hline
\end{tabular}

boundary established. The total number of case managers increased to 10.5. Although the psychiatrist and the psychologist had responsibility only for adult referrals, the other case managers also worked with the elderly. Referral criteria were unchanged. The team was fully trained in the use of the ICD-10 diagnostic system (World Health Organization, 1992).

The team operated a case management system. where major diagnostic and management decisions were reached through multidisciplinary discussion at regular team meetings. Once service criteria were agreed among team members, they were disseminated to referrer groups, particularly local primary care teams. This included referral procedures and criteria, target response times, and a description of the team's new skill mix.

Data was collected retrospectively over two sixmonth periods from January to June 1992 (TIme 1), and from January to June 1993 (Time 2). All referrals made to the team during these two periods were examined. Diagnoses were made in accordance with the ICD-10 diagnostic system, and general functioning at initial contact measured using the Global Assessment Scale (GAS; Endicott et al, 1976). All referrers were sent a questionnaire asking about their satisfaction with the service (dertved from Tyrer \& Remington, 1979).

In evaluating the effect of changes in the service particular attention was paid to the overall demands on the service, to referrals between the ages of 16-65, and to the nature of these adult referrals. The dependent variables examined were (a) total number of referrals to the team, (b) total number of referrals per case manager, (c) severity of mental disorder of adult cases (with 'severe' defined as an organic state, manic or depressive disorder, schizophrenia, and other disorders in the schizophrenia group), (d) global functioning at initial contact, and (e) referrer satisfaction.

\section{Inappropriate referrals}

Of the $\mathbf{3 3 8}$ referrals made to the service in the two six-month periods (Time 1=125, Time 2=213) 194 were not included on the following grounds: referred to the old age service (61); moved out of the area, did not attend appointment, or referred to a non-mental health agency (97); re-referrals (36).

\section{Findings}

In total, 144 referrals were appropriate, and assessed (46 in Time 1 and 98 in Time 2). The total number of referrals per case manager was 6.5 in Time 1, and 9.3 in Time 2. The 'severity' of illness of adult cases showed a statistically significant increase in Time 2 compared with Time 1. There was a decline in the GAS scores (increasing impairment of functioning), which however did not reach statistical significance.

The response to the Referrers Satisfaction Questionnaire was small (34 respondents at Time 1 and $\mathbf{4 0}$ at Time 2) and made interpretation of this data difficult. However, the changes in the service were generally associated with greater satisfaction. The percentage of referrers satisfied with the speed of response of the service increased from $77 \%$ to $93 \%\left(x^{2}=2.57\right.$, d.f. $=1$, NS), with the quality of care from $77 \%$ to $90 \%$, continuity of care from $65 \%$ to $75 \%$, and discharge procedures from $64 \%$ to $81 \%$.

\section{Comment}

Our findings suggest the changes associated with implementing a multidisciplinary model within a sector team can enhance the effectiveness of the service provided. In this example, the number of referrals per case manager increased while remaining adequate for the service to process, there was a significant change in the diagnostic distribution of referrals, and the appropriateness of referrals increased as the proportion of those suffering from a psychotic illness grew. The scale of increase in total number of referrals exceeded that of total number of case managers, before and after the service changes. Therefore, these developments in themselves are unlikely to explain the shift in diagnostic distribution of new referrals. 
Before the multidisciplinary model was introduced the teams' referrals showed some evidence of 'up-market drift' (Donovan, 1982), with a preponderance of cases suffering more minor psychiatric conditions. While the number of referred patients suffering from severe mental illness increased significantly over time, global functioning scores did not. This suggests that minor illness 'in crisis' may also present with poor levels of functioning, and GAS scores when used together with diagnostic groups may prove to be useful in developing referral criteria.

It is difficult to evaluate the separate contributions of changes in referrer behaviour outside the team, and those of skill $\mathrm{mix}$ and working style within the team in promoting more appropriate referrals. Systematically developed and implemented referral guidelines have been shown to contribute to referrers' use of specialist services, but the effect of less specific measures, such as disseminating referral information described here, is less clear although likely to be considerably less powerful (Effective Health Care, 1994). Within the team, considerable planning and preparation was involved in implementing a new model of working within an established team. For instance, all members were encouraged to contribute to discussions about criterla for referral, assessment and management, and to agree priorities for their routine clinical work. The multidisciplinary model includes both the opportunity to share information and skills between members, at the same time recognising discrete skills which rest closely with one or other of the clinical disciplines. All case managers could work with the range of mental health problems, and were empowered in working with people presenting challenging management problems through regular team discussions, which always included the psychiatrist, and drew on the skdlls of all team members. The psychiatrist was able to provide timely advice and assessment. This was particularly appreciated in the management of people with psychotic symptoms, or behaviour which endangered themselves or others. It often enabled team members, as well as referring GPs, to develop their own management plan without relinquishing clinical responsibility for the patients' care. Concerns have arisen about the role of the psychiatrist as leader in teams like the one we have described (Sims, 1992). Our impression is that their clinical role is one which requires similarly energetic attention.

In summary, the introduction of a multidisciplinary model was associated with increased appropriateness of referrals to this communitybased service. It is difficult to separate the relative contribution of different factors to these important changes. The systematic evaluation of team skdll mix, together with the effect of referrer education generally, and service guidelines more specifically, are likely to provide fertile ground for further health services research. This will be essential in informing the development of the most cost-effective mental health care across the range of treatment settings.

\section{Acknowledgements}

The authors would like to thank all the members of the Abbey Road Community Mental Health Team for their considerable work in helping to compile this data.

\section{References}

COOPER, J. E. (1990) Professional obstacles to implementation and diffusion of innovative approaches to mental health care. In Mental Health Care Delivery: Innovations, Impediments and Implementation (eds I. M. Marks \& R. A. Scott), pp. 233. Cambridge: Cambridge Untversity Press.

Donovan, C. M. (1982) Problems of psychiatric practice in community mental health centres. American Joumal of Psychiatry, 189, 456-69.

EFFECTIVE HEALTH CARE (1994) Implementing Clinical Practice Guidelines: Can Guideltnes be Used to Improve Clinical Practice? (Bulletin No. 8). Leeds: Untversity of Leeds.

ENDicotT, J., SPITZER, R. L., Fubiss, J. L., et al (1976) The Global Assessment Scale. Archtues of General Psychiatry. 3s. 766-771.

JARMAN, B. (1983) Identification of under-prtvileged areas. British Medical Journal, 288, 1705-1709.

MARRIOTT, S., MALONE, S., ONYETT, S., et al (1993) The consequences of an open referral system to a community mental health service. Acta Psychiatrica Scandinavica. 88, 93-97.

MERson, S., TYRER, P., ONYETT, S., et al (1992) Earty intervention in psychiatric emergencles: a controlled clinical trial. Lancet, $389,1311-1314$.

RrrchIE, J., Dick, D. \& LANGHAM, R. (1994) The Report of the Inquity tito the Care and Treatment of Christopher Clunis. London: HMSO.

Sims, A. (1992) The clinictan and the clinical team in the community. In Management Training for Psychiatrists (eds D. Bhugra \& A. Burns), pp. 103-109. London: Gaskell.

TYRER, P. \& REMmGTON, M. (1979) Controlled comparison of day hospital and out-patient treatment for neurotic disorder. Lancet, t, 1014-1016.

WORID HEALTH ORGANIZATION (1992) The Tenth Reulsion of the International Classification of Diseases and Related Health Problems (ICD-10). Geneva: WHO.

*Sarah Marriott, Research Fellow, College Research Unit, London SWIX; Angela Hassiotis, Senior Registrar in Learning Disabilities, St Charles Hospital, London W10 6DZ; Jonathon Ray, Audit Administrator, Abbey Road, Communtty Mental Health Team, London NW8 OEH; and Peter Tyrer, Professor of Community Psychiatry. St Charles Hospital, London W10 $6 \mathrm{DZ}$ and Consultant Psychiatrist, The North Paddington Community Mental Health Team, 209 Harrow Road, London W2 5EG

*Correspondence 